\title{
Three-Dimensional Computational Fluid Dynamic of Heat Transfer in Wall with Internal Heat Block
}

\author{
Ayad Khudhair Al-Nadawi ${ }^{1}$ and Hassan Naji Salman Al- Joboory ${ }^{2}$ \\ ${ }^{1}$ Middle Technical University (MTU), Institute of Technology-Baghdad, Electronic Technologies Department, Iraq. \\ ${ }^{2}$ Directorate of Renewable Energy, Ministry of Science and Technology (MoST), Baghdad, Iraq.
}

Received 8 April 2019; Accepted 10 June 2020

\begin{abstract}
The present paper deals with the computational dynamic simulation of heat transfer regimes involved with a wall heated by an embedded heat source. Such a case is present in the industrial thermal facilities and some HVAC applications. The thermal simulation model of the fixed heated flow was generated using CFD simulation software (FLOVENT 10.1). The Proposed wall is $(0.4 \mathrm{~m} \times 4 \mathrm{~m} \times 4 \mathrm{~m})$ in size and constructed from unfinished brickwork with outer leaf chosen from the same material, under atmospheric pressure and ambient temperature of $20^{\circ} \mathrm{C}$. The internal heating block is $(0.1 \mathrm{~m} \times 1 \mathrm{~m} \times 1 \mathrm{~m})$ in size, made of mild steel, embedded in the middle of the wall and of variable heating power. The temperature distribution in the wall was investigated at heat inputs range from $400 \frac{\mathrm{W}}{\mathrm{m}^{2}}$ to 1000 $\frac{W}{m^{2}}$. The temperature distribution of the heated wall's surface was shaped like a dome, with maximum temperature around of $23.2,24.5,25.6,26.7^{\circ} \mathrm{C}$ for $400,600,800$, and $1000 \frac{\mathrm{W}}{\mathrm{m}^{2}}$ respectively. It was also found that the temperature and heat flux is relatively higher in the centre and decrease gradually to the outlet.
\end{abstract}

Keywords: FloVent, simulation, heat block, temperature distribution, heated wall.

\section{Introduction}

Heated walls represent a heating technique that is used in some industrial applications such as furnaces. Therefore, analyzing heat transfer in wall with heated block is essential for developingand characterizing the performance of some industrial facilities and HVAC applications. The objective is to increase the amount of energy transferredbetween the wall and the surroundings. The temperature of the heated block increased and hence the temperature of the wall increased as well. Several studies were alreadyperformed on heating walls and window frames.

Gustavsen A and Dalehang A [1], presented a twodimensional fluid dynamics (CFD) simulations to study heat transfer rates for four horizontal window frames with complex internal cavities. Four different frames were studied, two were made of Polyvinyl Chloride (PVC) and two of Aluminum. Temperature was compared at selected locations on the frame. Small difference was found in the results from model to model. The simulation gives information about how air flows in window air cavities that can help engineers design improved window frames.

Meroney R. N, (2009) [2], provided a two-dimension vs three-dimensions simulations and the use of domain decomposition to simulate internal building with sealed openings. Domain decomposition worked well and provides

\footnotetext{
*E-mail address: ayadalnadawi@gmail.com ISSN: 1791-2377 @ 2020 School of Science, HHU. All rights reserved. doi:10.25103/jestr.133.09
}

a valuable analysis tool which can significantly reduce computational overhead.

Petel P [3], performed a steady state analysis on initial design for battery compartment using FloVENT 10.1. Improved designshow that hot air and hydrogen accumulation near roof is reduced to certain level. Additionally, Battery temperature is found to be $46^{\circ}-47^{\circ} \mathrm{C}$ for summer and $20^{\circ}$ $21^{\circ} \mathrm{C}$ for winter which is within ideal operating range for batteries even though after considering solar load. $\left(0^{\circ} \mathrm{C}\right.$ to $50^{\circ}$ C).

Filipponi M Et $\mathrm{Al}$ [4] analyzed the behavior of industrial furnace used in the forging industry. The furnace is $4.7 \mathrm{~m}$ height, $6.9 \mathrm{~m}$ width, and $18.55 \mathrm{~m}$ depth. These dimensions are relative to the internal space of the furnace, which is the space occupied by the fluid. Additionally, the simulation was conducted during the door opening. The CFD simulation showed that the main contributory in the amount of energy lost is convective heat flux and the reduction of the door opening time from $157 \mathrm{~s}$ to $40 \mathrm{~s}$ reduces the energy loss.

Landreau $M$. et al [5] presented a thermomechanical three-dimension modelling of a coke oven heating wall in order to estimate the maximal lateral pressure and to under stand mechanism of joints openings. The results of thermal calculation show that the coldest temperatures (around $300^{\circ} \mathrm{C}$ ) are located in heads of heating wall due to air where as the hottest are placed at the bottom of flues near the flame (around $\left.1300^{\circ} \mathrm{C}\right)$.

Koca A. et al [6] provided experimental information for heat transfer phenomena from radiant wall heating surfaces. Heating tests were done for three different location configurations which are the west wall, the north wall and the both combined. The findings proved that these setups were suitable to determine the system's heating output. The 
approximate average values of $5.7 \frac{\mathrm{W}}{\mathrm{m}^{2} \mathrm{~K}}$ and $2.7 \frac{\mathrm{W}}{\mathrm{m}^{2} \mathrm{~K}}$ were found respectively for the radiant and theconvective heat transfer coefficients.

Hao S. et al [7] proposed experimental study of a heat recovery system composed of the Chinese traditional heated wall and fireplace. Experimental tests were done on test rooms to evaluate the surface temperature distribution and thermal performance of the heated wall in response to several combustion patterns. Indoor air temperature was increased by 3.3to $4.0^{\circ}$ Cover the control room and the temperature distribution of the heated wall's surface was nonuniform, with a temperature range of $116.03^{\circ} \mathrm{C}$. The results show that the combustion pattern had a major impact on the initial and peak temperatures of the wall body's surface during combustion. The present study is based on the computational fluid dynamics using FLoVENT 10.1 software. The study was done with various heated block's powers to determine the maximum temperature distribution that can be generated inside the wall. The steady state approach used in the simulation and steady solution converged in all of the tests.

\section{Mathematical Representation}

FloVENT10.1 solves the field variables which are $u, v$ and $w$, velocity components along the $x, y$ and $z$ coordinates respectively, the pressure $p$, and the temperature $T$ of the fluid and/or solid materials [8]. The numerical solution of heat transfer problems is obtained by solving three differential equations in this study. These equations are conservation of mass, conservation of momentum and conservation of energy. For instance, $\mathrm{u}, \mathrm{v}$ and $\mathrm{w}$ satisfy the momentum conservation equations in the three coordinate directions. The pressure does not itself satisfy a conservation equation but is derived from the equation of continuity which is a statement in differential form of the conservation of mass. Finally, temperature satisfies the conservation equation of thermal energy [8].

\section{Solution Methodology}

FloVENT used a CFD technique which is based on the finite volume method (FVM). In FVM, the conservation equations are discretized by subdivision of the domain of integration into a set of contiguous finite volumes over each of which the conservation equations are expressed in algebraic form. These finite volumes are referred to as grid cells, control cells or quite simply as cells. The equations' results relate the value of a variable in a cell to its value in the nearest neighbor cell [8]. The layout forthe grid and velocities for a grid having a total of $224(=7 \times 8 \times 4)$ cells is shown in figure 1 .

$3 \mathrm{D}$

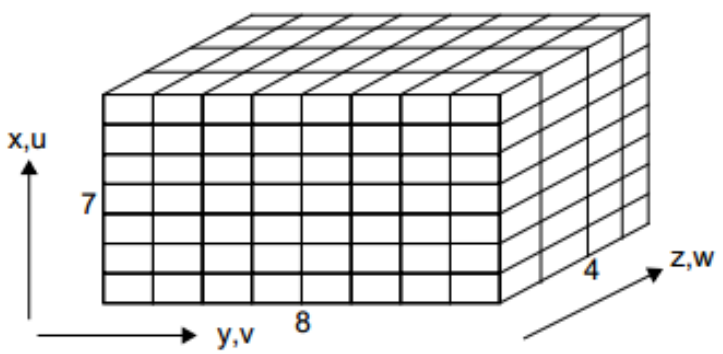

Fig. 1. The layout for the grid.

For instance, for the temperature $\mathrm{T}$, the temperature variable can be calculated by the following equation:
$\mathrm{T}=\frac{\mathrm{C}_{0} \mathrm{~T}_{\mathrm{O}}+\mathrm{C}_{1} \mathrm{~T}_{1}+\mathrm{C}_{2} \mathrm{~T}_{2}+\mathrm{C}_{3} \mathrm{~T}_{3}+\mathrm{C}_{4} \mathrm{~T}_{4}+\mathrm{C}_{5} \mathrm{~T}_{5}+\mathrm{C}_{6} \mathrm{~T}_{6}+\mathrm{s}}{\mathrm{C}_{1}+\mathrm{C}_{2}+\mathrm{C}_{3}+\mathrm{C}_{4}+\mathrm{C}_{5}+\mathrm{C}_{6}+\mathrm{C}_{7}}$

Where

$\mathrm{T}_{0}$ Temperature value in the old-time step.

$\mathrm{T}_{1}, \mathrm{~T}_{2}, \mathrm{~T}_{3}, \mathrm{~T}_{4}, \mathrm{~T}_{5}, \mathrm{~T}_{6}$ Temperature values of the six neighbouring cells.

$\mathrm{C}_{\mathrm{n}}$ represent the coefficients that link the in-cell value to each of its neighbor-cell values.

$\mathrm{s}_{\mathrm{n}}$ represent the influences of the boundary conditions (if any), forinstance, a source of heat. There are $5 \mathrm{n}$ equations to solve equations for each of the field variables $\mathrm{T}, \mathrm{u}, \mathrm{v}, \mathrm{w}, \mathrm{P}$ [3].

\section{Derivation of Finite-Volume Equations}

We will call the equations derived in [8]. Firstly, let's consider a transient, one-dimensional, uniform grid in the $\mathrm{X}$ direction, figure 2 . Single grid cell can be illustrated in figure 3.

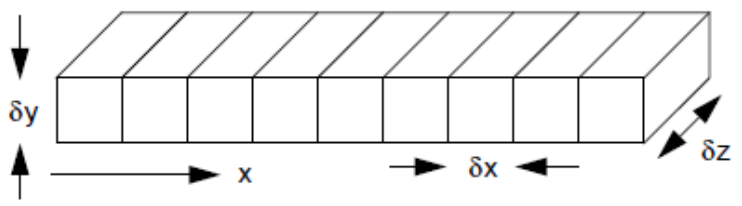

Fig. 2. Grid in the X-direction.

Cell volume:

$\mathrm{V}_{\mathrm{p}}=\delta \mathrm{x} \delta \mathrm{y} \delta \mathrm{z}$

$\mathrm{x}$-direction face area:

$\mathrm{A}_{\mathrm{x}}=\delta \mathrm{y} \delta \mathrm{z}$

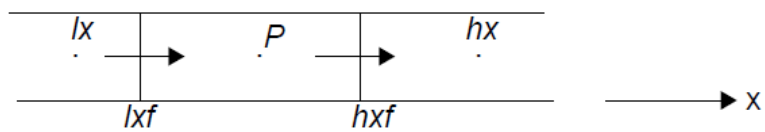

Fig. 3. Grid Cell.

The finite volume equations in deferential form: Continuity equation.

$$
\frac{\partial \rho}{\partial t}+\frac{\partial \rho u}{\partial x}=0
$$

For three-dimensions, the first term in the continuity equation become,

$\int_{z} \int_{y} \int_{x} \frac{\partial \rho}{\partial t} d x d y d z=\left(\frac{\rho_{p}-\rho_{t}}{\partial t}\right) \delta x \delta y \delta z=\left(\frac{\rho_{p}-\rho_{t}}{\partial t}\right) V p(3)$

The second term in the continuity equation become,

$\int_{z} \int_{y} \int_{x} \frac{\partial \rho u}{\partial x} d x d y d z=\int_{z} \int_{y}\left[(\rho u)_{h x f}-\right.$

$\left.(\rho u)_{l x f}\right] d y d z$

$=(\rho u)_{h x f} \delta y \delta z-(\rho u)_{l x f} \delta y \delta z$

$=(\rho u)_{h x f} A x-(\rho u)_{l x f} A x$

So, the final equation is:

$\left(\frac{\rho_{p}-\rho_{t}}{\partial t}\right) V p+(\rho u)_{h x f} A x-(\rho u)_{l x f} A x=0$

Which means, 
Rate of increase of mass in cell + Difference between outflow and inflow $=0$

and for steady state or constant density:

Mass outflow - Mass inflow $=0$

Temperature equation.

$\frac{\partial\left(\rho C_{P} T\right)}{\partial t}+\frac{\partial\left(\rho C_{P} u T\right)}{\partial x}-\frac{\partial}{\partial x}\left(\frac{\lambda \partial T}{\partial x}\right)=S$

Transient term:

$\int_{z} \int_{y} \int_{x} \frac{\partial\left(\rho C_{P} T\right)}{\partial t} d x d y d z=\left[\frac{\partial\left(\rho C_{P} T\right)_{p}-\partial\left(\rho C_{P} T\right) t}{\partial t}\right] \times V_{p}$

Convection Term:

$\int_{z} \int_{y} \int_{x} \frac{\partial\left(\rho u C_{P} T\right)}{\partial t} d x d y d z=\int_{z} \int_{y}\left[\partial\left(\rho u C_{P} T\right)_{h c f}-\right.$ $\left.\partial\left(\rho u C_{P} T\right)_{l x f}\right] d y d z$

$=\partial\left(\rho u C_{P} T\right)_{h x f} A x-\partial\left(\rho u C_{P} T\right)_{l x f} A x$

Where,

$\mathrm{T}_{\mathrm{hxf}}=\mathrm{T}_{\mathrm{p}}, \rho_{\mathrm{hxf}}=\rho_{\mathrm{p}}$

$\mathrm{T}_{\mathrm{lxf}}=\mathrm{T}_{\mathrm{lx}}, \rho_{\mathrm{lxf}}=\rho_{\mathrm{lx}}$

Conduction Term:

$\int_{z} \int_{y} \int_{x}-\frac{\partial}{\partial x}\left(\frac{\lambda \partial T}{\partial x}\right) d x d y d z=-\int_{z} \int_{y}\left[\frac{\lambda \partial T}{\partial y}-\right.$ $\left.\frac{\lambda \partial T}{\partial y}\right] \times d y d z$

$=-\left(\lambda\left(\frac{T_{h x}-T_{p}}{\delta x}\right)-\lambda\left(\frac{T_{p}-T_{l x}}{\delta x}\right)\right) \times A x$

That is, outflow - inflow of heat by conduction.

Heat source term:

$\int_{Z} \int_{y} \int_{x} S d x d y d z=S p \times V p$

Applying all of these terms in equation (6), we will get the final equation. Keeping in mind, for steady state solution the transient term will be zero and for conduction only the convection term will be zero too.

\section{Wall-Heated Block Modelling}

The main goal of the current study is to simulate the threedimension wall with internal heated block to see the temperature distribution inside the wall under different magnitudes of heat generated by the heated block. FloVENT 10.1 is used to design the wall and the heated block geometry as shown in figure 4 .

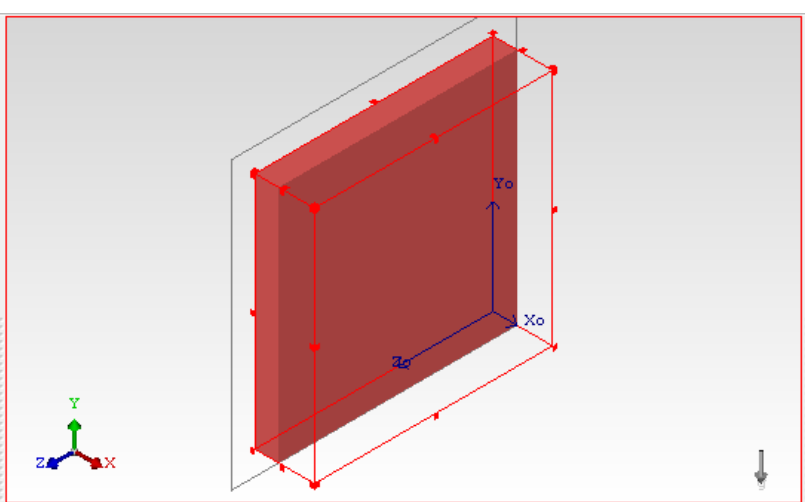

Fig. 4. Geometry used for simulation.

The wall size is of dimension $(0.4 \mathrm{~m} \times 4 \mathrm{~m} \times 4 \mathrm{~m})$, unfinished brickwork with outer leaf is chosen to be the material of the wall. On the other hand, a mild steel block is inserted in the middle of the wall as shown in figure 5 . The properties of fluid and materials are drawn from the properties provided by FloVENT 10.1. The block dimension is $(0.1 \mathrm{~m} \times 1 \mathrm{~m} \times 1 \mathrm{~m})$. The ambient temperature is set at $20^{\circ} \mathrm{C}$ with $10 \frac{\mathrm{W}}{\mathrm{m}^{2} . K}$ heat transfer coefficient and constant pressure. Fixed heat transfer was used in the heated block and CFD analysis were carried out for different magnitude of 400,600,800, and $1000 \frac{\mathrm{W}}{\mathrm{m}^{2}}$ generated in the heated block. The total number of grid cells were 4352 with Fine system grid. The solution converged in all of the experiments.

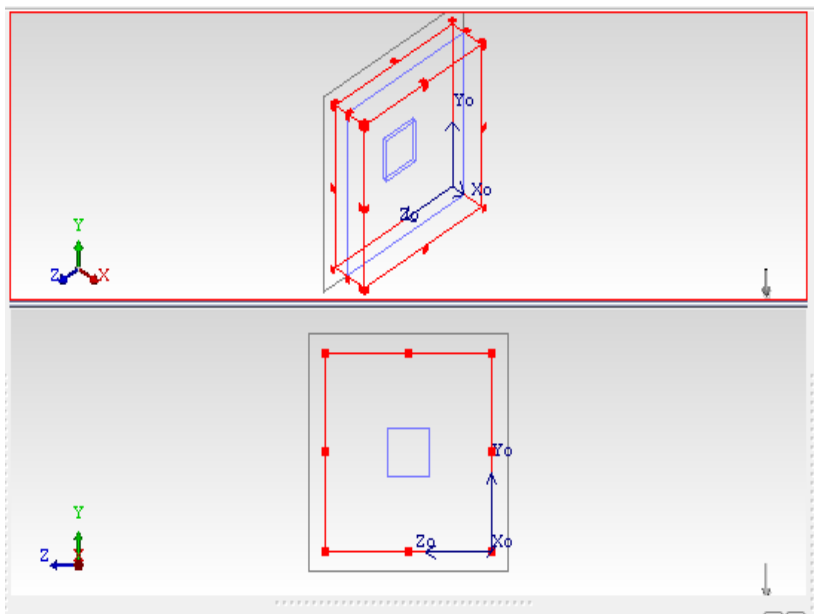

Fig. 5. Schematic of the wall used for simulation.

\section{Results and Discussion}

At first, in this study the internal heat block was embedded inside a wall. Figure 6 shows the simulated temperature and heat flux distribution in the heated wall at $400 \frac{\mathrm{W}}{\mathrm{m}^{2}}$. It can be seen that the temperature and heat flux is relatively higher at the centre and decrease gradually towards the outlet. Figure 7,8 , and 9 show the same trend for $600,800,1000 \frac{W}{m^{2}}$ respectively. 


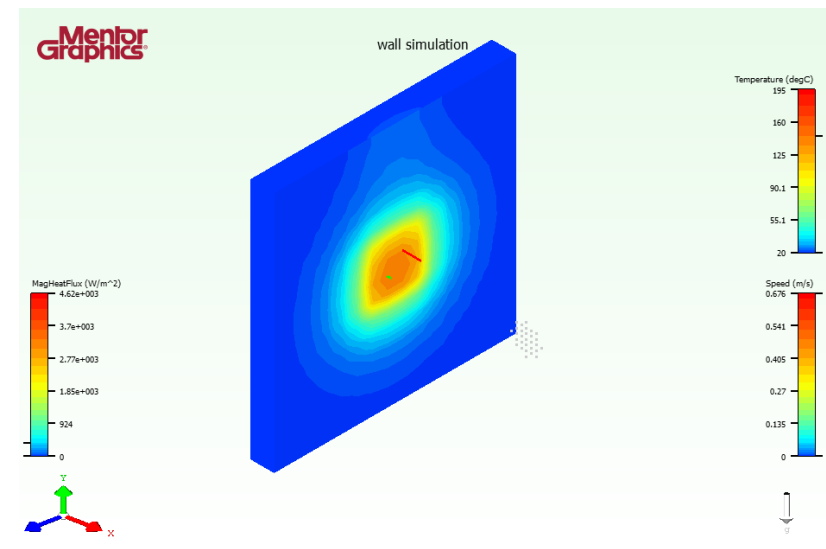

Fig. 6. Temperature and heat flux distribution in the heated block at 400 $\frac{W}{m^{2}}$.

It is worthy to mention that the maximum temperature was $195^{\circ} \mathrm{C}$, figure 6 . The temperature gradually increased from 20 ${ }^{\circ} \mathrm{C}$ up to the maximum temperature. That behaviour depends on the position of the heated block.

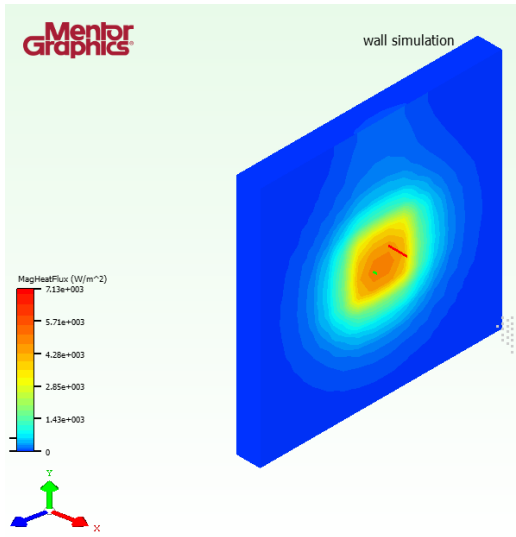

Fig. 7. Temperature and heat flux distribution in the heated blockat 600 $\frac{W}{m^{2}}$.

Additionally, the same behavior can be seen in figure 7 for $600 \frac{\mathrm{W}}{\mathrm{m}^{2}}$ results. However, the maximum temperature was $270{ }^{\circ} \mathrm{C}$. The range between 400 and $600 \frac{\mathrm{W}}{\mathrm{m}^{2}}$ results is $75{ }^{\circ} \mathrm{C}$ and the deviation between the two tests was $38 \%$.

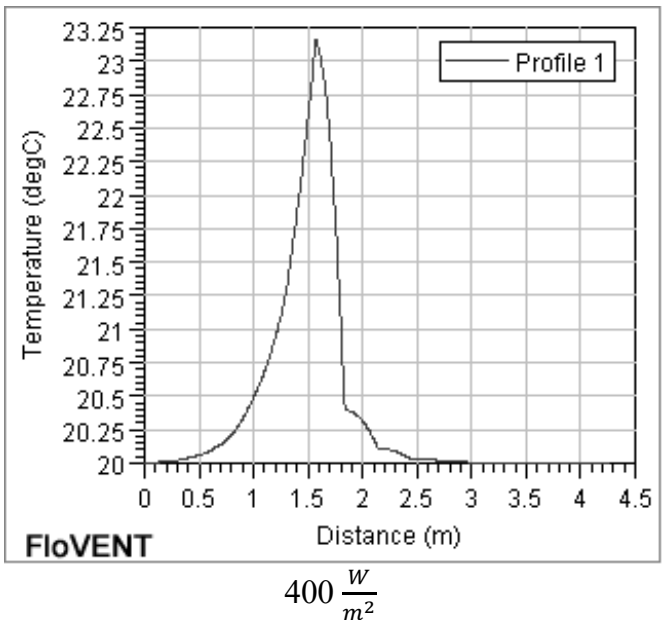

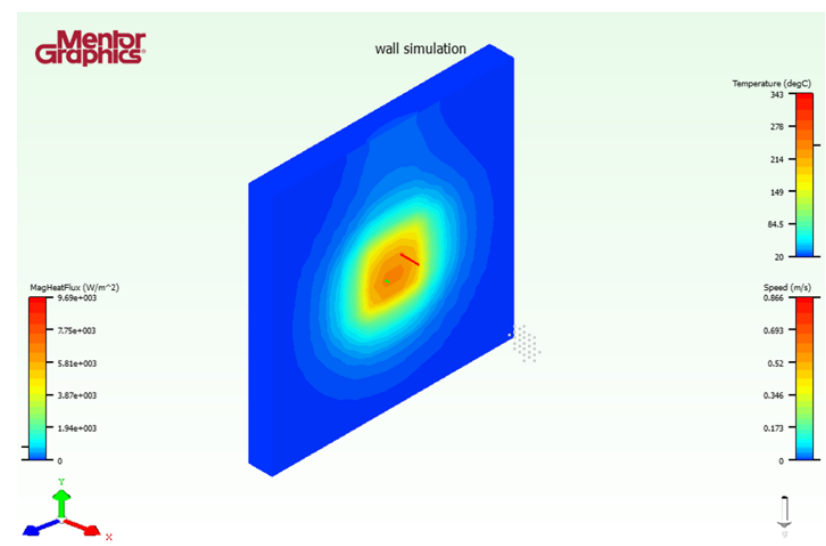

Fig. 8. Temperature and heat flux distribution in the heated blockat 800 $\frac{W}{m^{2}}$.

On the other hand, it is expected that the temperature will rise in the same way when the heater power increased. Figure 8 show the results for $800 \frac{\mathrm{W}}{\mathrm{m}^{2}}$. It is clear that the maximum temperature is $343^{\circ} \mathrm{C}$. That means the range between 600 and $800 \frac{\mathrm{W}}{\mathrm{m}^{2}}$ is $73^{\circ} \mathrm{C}$. Whereas the deviation between 400 and 800 $\frac{W}{m^{2}}$ results is $175 \%$.

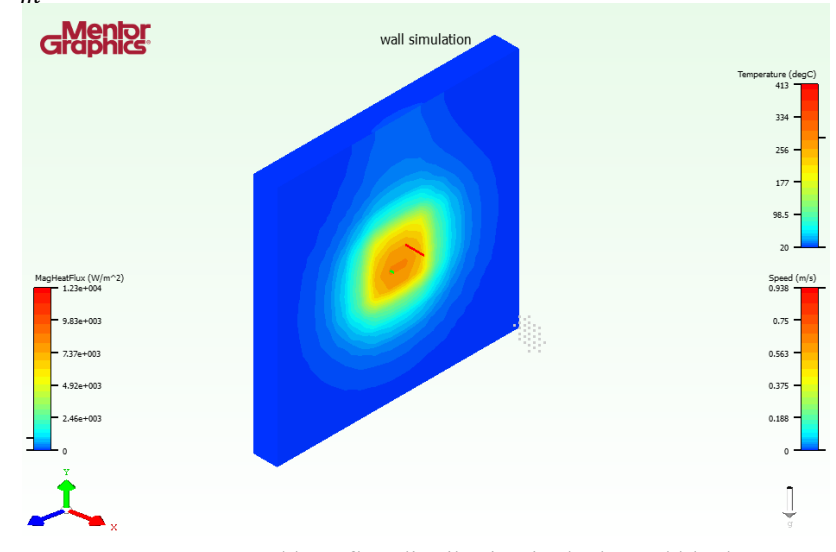

Fig. 9. Temperature and heat flux distribution in the heated block at 1000 $\frac{W}{m^{2}}$.

Further, the maximum temperature for $1000 \frac{\mathrm{W}}{\mathrm{m}^{2}}$ test is 413 ${ }^{\circ} \mathrm{C}$, figure 9 . So, the range between 800 and $1000 \frac{\mathrm{W}}{\mathrm{m}^{2}}$ is $70{ }^{\circ} \mathrm{C}$. Therefore, the deviation between 400 and $1000 \frac{W}{m^{2}}$ is more than $100 \%$. Thus, increasing the heated block power from 400 to $1000 \frac{\mathrm{W}}{\mathrm{m}^{2}}$ lead to increase the maximum temperature as well as the general temperature in the heated block.

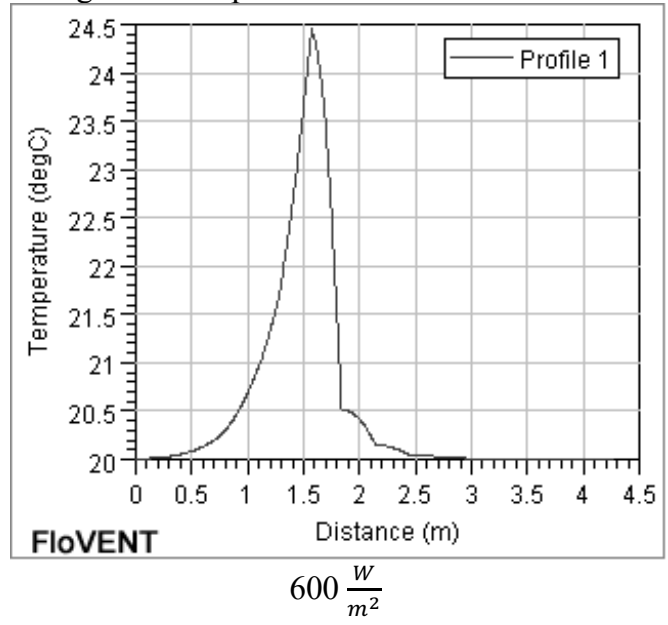




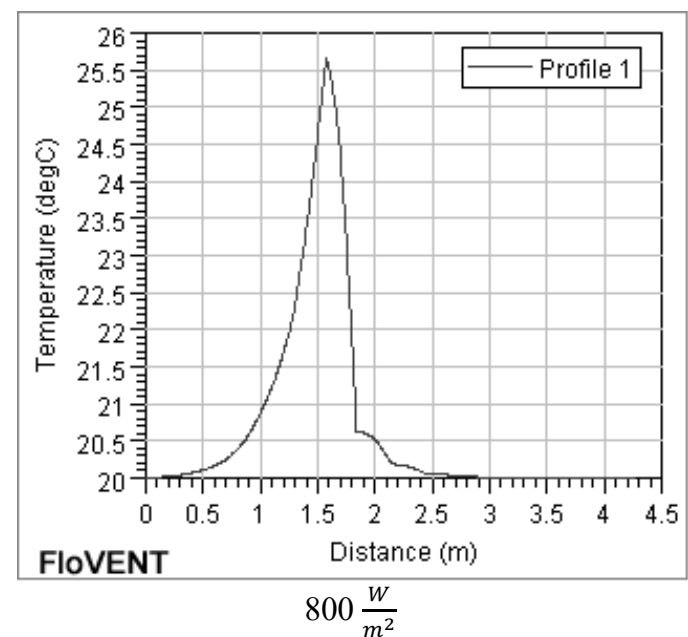

Fig. 10. Temperature distribution in the wall.

Figure 10 show the temperature distribution inside the wall. It is obvious that when the power of the heated block increased the temperature inside the wall increased as well. The maximum temperature is around $23.2,24.5,25.6,26.7^{\circ} \mathrm{C}$ for $400,600,800$, and $1000 \frac{\mathrm{W}}{\mathrm{m}^{2}}$ respectively. Clearly, all the tests prove that the maximum temperature happened
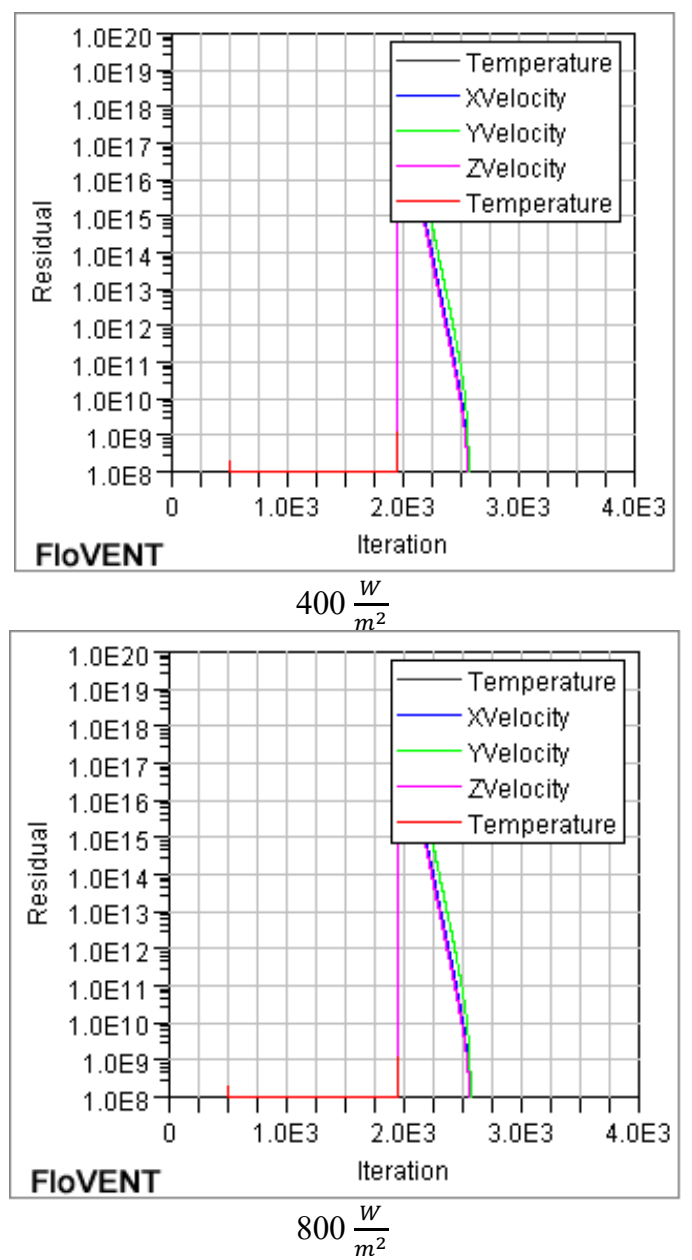

Fig. 11. Iteration convergence of the tests.

As can be seen in figure 11, after the initial startup period, thatthe solution imbalances gradually decrease as the solution progresses. After approximately $2.5 \times 10^{3}$ iterations, theresiduals are reduced to $1 \times 10^{8}$ in all of the test results.

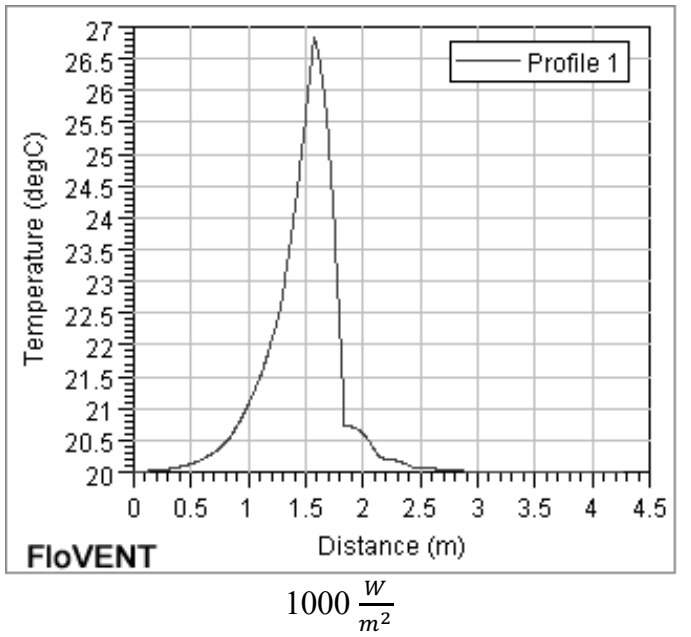

somewhere around $1.5 \mathrm{~m}$. The temperature started to rise gradually from $20^{\circ} \mathrm{C}$ up to the maximum temperature and then it starts to fall down till it reach again to it's starting temperature. The temperature achieves it's starting magnitude at $3 \mathrm{~m}$. All of the curves show the shape like dome or the probability density function. That is because of the location of the heated block inside the wall.
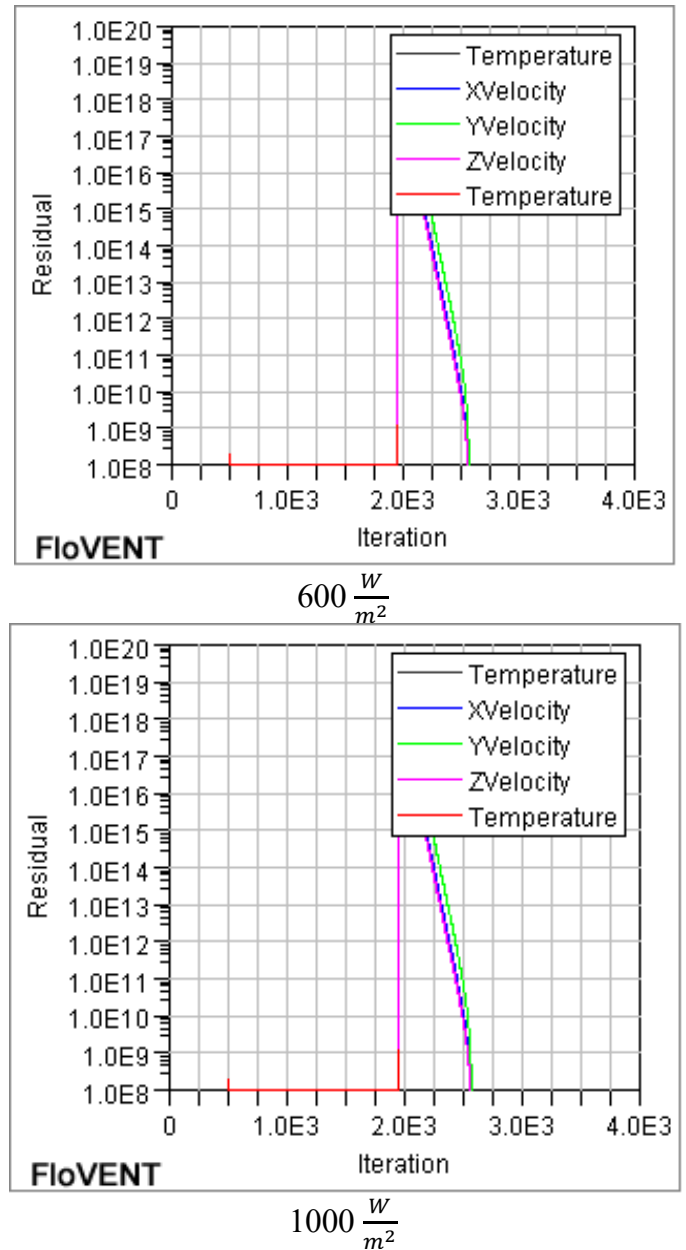
Computational fluid dynamics has been used to simulate heat transferin wall with internal heat block by using FloVENT 10.1. The results show that the temperature increased with the increasing heat flux. It was found that the temperature distribution of the heated wall's surface was have similar behaviour in all of the tests, with maximum temperature around of $23.2,24.5,25.6,26.7^{\circ} \mathrm{C}$ for $400,600,800$, and 1000 $\frac{W}{m^{2}}$ respectively.Additionally, it is suggested to the heat transfer characteristic in transient state. This can be used to improve the performance of many applications such as furnaces and heated elements in pool boiling.

This is an Open Access article distributed under the terms of the Creative Commons Attribution License

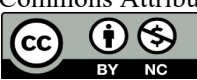

\section{References}

[1] Gustaven A.,Kohler C., Dalehang A.,Arasteh D., “ TwoDimensional Computational Fluid Dynamics andConduction Simulations of Heat Transfer in Horizontal Window Frames with Internal Cavities", Ernest Orlando Lawrence Berkeley National Laboratory, Berkeley, CA (United States). https://digital.library.unt.edu/ark:/67531/metadc900651/

[2] Robert N. Meroney, "CFD Prediction of Airflow in buildings for Natural Ventilation", 11th Americas Conference on Wind Engineering, San Juan, Puerto Rico, June 22-26, 2009.

[3] Patel P," Design Of Cooling And Ventilation For Telecommunication Shelter At High Altitude", Master Of Science In Mechanical Engineering, The University Of Texas At Arlington, May 2015.

[4] Filipponi M, Rossi F, Presciutti A, De Ciantis S, Castellani B, And Carpinelli A, "Thermal Analysis of An Industrial Furnace", Energies 2016, 9, 833; Doi:10.3390/En9100833,
Www.Mdpi.Com/Journal/Energies

[5] LandreauM., IslerD., GasserA., BlondE., DanielJ.-L.,"Modelling of a coke oven heating wall", 6th European Coke and Ironmaking Congress 2011, Jun 2011, Dusserdolf, Germany. pp.20-25, 2011. https://hal.archives-ouvertes.fr/hal-00634664

[6] Koca A., Gemici Z., Topacoglu Y., Cetin G., Acet R.C., Kanbur B. B.," Experimental investigation of heat transfer coefficients betweenhydronic radiant heated wall and room", Energy and Buildings 82 (2014) 211-221.

Hao S. , Xu Y., Yu C., Song Y., Lin Z.," Experimental Investigation of the SurfaceTemperature Distribution and Thermal Performance of an Intermittent Combustion ChineseHeated Wall", Advances in Materials Science and Engineering, Volume 2018, 13 pages.https://doi.org/10.1155/2018/3457950

[7] FloVENT® Background Theory Reference Guide Software Version 10.1, Mentor Graphics Corporation.

\section{Nomenclature}

\begin{tabular}{|c|c|}
\hline A & Area. \\
\hline $\mathrm{C}$ & Represent the coefficients that link the in-cell value to each of its neighbour cell values. \\
\hline FVM & Finite volume method. \\
\hline HVAC & Heat ventilation and air condition. \\
\hline $\mathrm{p}$ & Pressure. \\
\hline $\mathrm{S}$ & Heat source. \\
\hline s & represent the influences of the boundary conditions \\
\hline $\mathrm{T}$ & Temperature. \\
\hline$u, v, w$ & Velocity components. \\
\hline$x, y, z$ & Coordinates. \\
\hline Greek symbols & \\
\hline$\rho$ & Density. \\
\hline Subscripts & \\
\hline o & Value in the old-time step. \\
\hline $1,2,3,4,5,6$ & Values of the six neighbouring cells. \\
\hline
\end{tabular}

